\title{
The interaction between atrazine and the mineral horizon of soil: a spectroscopic study
}

\author{
Marianna Czaplicka $^{1}$ • Hanna Barchanska ${ }^{2}$ - Katarzyna Jaworek ${ }^{1}$. \\ Bożena Kaczmarczyk ${ }^{3}$
}

Received: 29 June 2017 / Accepted: 22 September 2017 / Published online: 18 October 2017

(C) The Author(s) 2017. This article is an open access publication

\begin{abstract}
Purpose In this paper, an attempt was made to explain the long-lasting occurrence of atrazine in soil. Despite the fact that this herbicide has been banned in European Union 10 years ago, it is still detected in the environment.

Materials and methods Soil samples (organic and mineral horizon), $\mathrm{SiO}_{2}$ and $\mathrm{Al}_{2} \mathrm{O}_{3}$ sorbents were spiked with atrazine. The ultrasound-assisted extraction coupled with gas chromatography-electron capture detector was performed to establish the atrazine recovery depending on the type of soil horizon and sorbent. Fourier transform infrared spectroscopy (FTIR) analysis was conducted to determine the type of interactions between atrazine and sorbents.

Results and discussion The atrazine recovery was lower for the mineral horizon (15\%) compared to the organic horizon $(63 \%)$. This finding suggests an interaction between atrazine and the mineral components of soil. Therefore, attempts have been made to explain atrazine's interaction with the main mineral components of soil, $\mathrm{SiO}_{2}$ and $\mathrm{Al}_{2} \mathrm{O}_{3}$, and to investigate the influence of $\mathrm{pH}$ on atrazine's behaviour in soil. The atrazine recoveries were 86.5 and $10.7 \%$ for $\mathrm{Al}_{2} \mathrm{O}_{3}$ and $\mathrm{SiO}_{2}$, respectively. The obtained results demonstrated that the
\end{abstract}

Responsible editor: Fabio Scarciglia

Hanna Barchanska

hanna.barchanska@polsl.pl

1 Institute of Environmental Engineering Polish Academy of Science, M. Sklodowska-Curie 34 Str., 41-819 Zabrze, Poland

2 Department of Inorganic, Analytical Chemistry and Electrochemistry, The Silesian University of Technology, B. Krzywoustego 6 Str., 44-100 Gliwice, Poland

3 Centre of Polymer and Carbon Materials, M. Sklodowska-Curie 4 Str., 41-800 Zabrze, Poland protonated atrazine exhibits stronger interactions with the soil mineral layer (recovery below $0.1 \%$ ) in comparison to molecular form of atrazine (recovery $86 \%$ ). FTIR results suggested interactions between atrazine and $\mathrm{SiO}_{2}$. FTIR analysis revealed that 1,3,5-azidine ring interacts with $\mathrm{SiO}_{2}$ molecule. Conclusions In acidic soil, atrazine remediation is limited, especially if the soil contains minerals with high $\mathrm{SiO}_{2}$ contents. This situation may cause the long-lasting persistence of atrazine in soil.

Keywords Atrazine · FTIR · Interaction · Mineral horizon · Soil

\section{Introduction}

The triazine group of herbicides is the most well known and has been widely used around the world for more than 50 years. Triazines accumulate in leaves and meristems, where they inhibit the Hill reaction by blocking photosynthesis by binding with tyrosinase, the enzyme responsible for the oxidation of polyphenols to quinones (Mou et al. 2011). The simplicity and low cost of atrazine (2-chloro-4-ethylamino-6isopropylamino-1,3,5-triazine) synthesis make it the most popular triazinic compound herbicide. It is a selective herbicide that is applied at a rate of $1 \mathrm{~kg} \mathrm{ha}^{-1}$ to corn, sorghum, sugarcane, pineapple fields and orchards as well as applied to non-agricultural lands to control broad-leaf and grassy weeds. Although it has been banned in European Union countries, it is still in use in other regions of the world. For instance, in the USA, almost 30,000 t of atrazine are applied annually (Hase et al. 2008). Because of its intense use, stability and ability to translocate in the environment (Roustan et al. 2014; Yixin et al. 2014; Nachimuthu et al. 2016), atrazine is present in soils and waters worldwide (Hase et al. 2008; Merini et al. 
2009; Feria-Reyes et al. 2011; Li et al. 2012; Farlin et al. 2013; Geng et al. 2013; Ji et al. 2015; Ouyang et al. 2016a). Atrazine is suspected to be an endocrine disruptor and is linked to Parkinson's disease in humans (Filipov et al. 2007; Brodeur et al. 2009). Atrazine has also been reported to exhibit reproductive toxicity in mammals (Wilhelms et al. 2006; Weselak et al. 2007).

The fate of atrazine after it enters the soil is dependent on its sorption properties, water solubility, polarity and its ionic nature. The physico-chemical characteristic of atrazine is presented in Table 1. Other factors that influence atrazine's stability in soil are its texture, organic matter content, water content, the presence of microorganisms and the soil $\mathrm{pH}$ (Wang et al. 1999).

Minerals and organic matter (humic substances, HS) in soil, which are differentiated into fulvic acids, humic acids and humin, are largely responsible for the adsorption of atrazine (Ouyang et al. 2016b). The binding of atrazine to HS has been the subject of many research papers (Neto et al. 1994; Garbin et al. 2007; Prosen et al. 2007; Hutta et al. 2011), but the complex interactions are the reason for a controversy discussion on the mechanisms by which these substances are bound: electron transfer, hydrogen bonding, proton transfer resulting in ionic bonds or partitioning into the hydrophobic domains of HS. Other researchers explain the formation of well-known non-extractable chloro-s-triazine residues in soil by chemical binding to HA by heteroatomic bonds after the substitution of a chlorine atom (Neto et al. 1994; Yu and Cole 1997; Davies and Jabeen 2003; Prosen and Zupancic-Kralj, 2005, Prosen et al. 2007). Many researchers have demonstrated the influence of the mineral components of soil on the sorption of atrazine (Davies and Jabeen 2003; GonzalezPradas et al. 2003; Lesueur et al. 2008; Feria-Reyes et al. 2011; Barchanska et al. 2013; Prado et al. 2014). $\mathrm{SiO}_{2}$ and $\mathrm{Al}_{2} \mathrm{O}_{3}$ are the predominant minerals present in soil. The mineralogical composition of soil includes quartz, plagioclase, kalifeldspar, calcite, mica, kaolinite and residual phase (clay minerals) (Norra et al. 2008). The role of minerals on atrazine adsorption in soil is not well documented. Gilchrist et al. (1993) found that the adsorption capacity of clays for atrazine followed the order of montmorillonite $>$ illite $>$ kaolinite.

The literature review and the results of our experiments (Barchanska et al. 2013) prompted us to carry out a more comprehensive study on the interaction between atrazine and selected mineral compounds in soil.

The present work aims to contribute to a better understanding of atrazine's interactions with the main inorganic constituents of clay minerals, silica and alumina and to investigate the influence of $\mathrm{pH}$ on atrazine's behaviour in soil.

As a tool for atrazine determination in soil samples, ultrasound-assisted extraction (UAE) coupled with gas chromatography-electron capture detector (GC-ECD) was chosen. This extraction technique does not provide recovery
Table 1 Physico-chemical characteristic of atrazine (PPDB)

\begin{tabular}{ll}
\hline Parameter & Value \\
\hline Solubility in water $\left(\mathrm{mg} \mathrm{L}^{-1}, 22^{\circ} \mathrm{C}, \mathrm{pH} 7\right)$ & 33 \\
$\log \mathrm{K}_{\mathrm{ow}}\left(25^{\circ} \mathrm{C}\right)$ & 2.5 \\
Soil sorption constant, $\mathrm{K}_{\mathrm{oc}}$ & 100 \\
Melting point $\left({ }^{\circ} \mathrm{C}\right)$ & $171-174$ \\
Vapour pressure $\left(20^{\circ} \mathrm{C} ; \times 10^{6} \mathrm{mmHg}^{-3}\right.$ & 0.3 \\
Henry's law constant $\left(\mathrm{Pa} \mathrm{m}^{-3} \mathrm{~mol}^{-1}\right)$ & $1.5 \times 10^{-4 *}$ \\
$\mathrm{p} K_{\mathrm{a}}$ & 1.70 \\
\hline
\end{tabular}

percentages as high as microwave-assisted extraction (MAE), but it does not break the bond between atrazine and inorganic soil components (Gevao et al. 2000); therefore, it is suitable for the investigation of the interaction in the herbicide-soil matrix. For the investigation of atrazine's interaction with the selected mineral compounds, Fourier transform infrared spectroscopy (FTIR) and elemental analysis were applied.

\section{Materials and methods}

\subsection{Chemicals and reagents}

The standard for atrazine was obtained from Riedel-de Haën (Seelze, Germany). Atrazine stock standard solution was prepared by dissolving atrazine in methanol.

Methylene chloride, sodium hydroxide and hydrochloric acid, which were all of analytical grade, were provided by CHEMPUR (Piekary Sl. Poland). The characteristics of $\mathrm{Al}_{2} \mathrm{O}_{3}$ (Bellefonte, PA, USA) and $\mathrm{SiO}_{2}$ used (Merck, Darmstadt, Germany) are shown in Table 2.

\subsection{Instrumentation}

Qualitative and quantitative chromatographic analyses were performed using a PerkinElmer Clarus 500 gas chromatograph (GC) (Waltham, MA, USA) equipped with an electron capture detector (ECD) and a $30 \mathrm{~m} \times 0.25 \mathrm{~mm}$ i.d. DB-5MS column with a film thickness of $0.25 \mu \mathrm{m}$.

The column temperature was programmed to increase from 150 to $275^{\circ} \mathrm{C}$ at a rate of $10^{\circ} \mathrm{C} \mathrm{min}^{-1}$, maintain for $3 \mathrm{~min}$ and then increase from 275 to $300{ }^{\circ} \mathrm{C}$ at a rate of $16^{\circ} \mathrm{C} \mathrm{min}^{-1}$. The temperature of the injector was $250^{\circ} \mathrm{C}$, and the temperature of the detector was $310^{\circ} \mathrm{C}$.

The investigated compound was identified by its retention time. The qualitative analysis was performed using the external standard method. Limit of detection was calculated as three times the signal to noise ratio, whereas the limit of quantification, determined as three times the limit of detection, was equal to $4.5 \mathrm{ng} \mathrm{g}^{-1}$. 
Table 2 Physical characteristic of sorbents

\begin{tabular}{lcl}
\hline Parameter & $\mathrm{Al}_{2} \mathrm{O}_{3}$ & $\mathrm{SiO}_{2}$ \\
\hline Particle size & 150 & $70-230$ \\
Surface area $\left(\mathrm{mm}^{2} \mathrm{~g}^{-1}\right)$ & 155 & $450-540$ \\
Pore size $(\AA)$ & 56 & 60 \\
$\mathrm{pH}$ & 9.5 & 7.5 \\
\hline
\end{tabular}

For atrazine extraction from the soil samples, an ultrasound bath POLSONIC 2 (Warsaw, Poland) with a frequency of $40 \mathrm{kHz}$ and ultrasound power of $2 \times 100 \mathrm{~W}$ was used.

The infrared spectra of atrazine and the mixtures of atrazine and sorbents 1 as reported in Figs. 1 and 2 were recorded at room temperature $\left(25^{\circ} \mathrm{C}\right)$ in the frequency range 4000 $400 \mathrm{~cm}^{-1}$ with a Fourier transform infrared spectrophotometer 40FTS BioRad (Hercules, CA, USA) using 32 scans and a resolution of $2 \mathrm{~cm}^{-1}$. Samples were analysed as $\mathrm{KBr}$ pellets.

The soil composition was determined using a wavelengthdispersive X-ray fluorescence spectrometer manufactured by RIGAKU ZSX Primus (Japan).

\subsection{Sample preparation}

\subsubsection{Soil sample preparation}

This study consisted of preparing atrazine-spiked soil samples from pesticide-free soil collected in a forest from the surface layer (organic horizon) and from a depth of $1 \mathrm{~m}$ (mineral horizon). The detailed characteristics of primary soil samples are shown in Table 3.

Soil pH was determined according to ISO 10390:2005, the Kappena method was used for hydrolytic acidity determination and the sum of exchangeable cations was found according to the Pallman procedure. On the basis of these data, the sorption capacity was calculated. The organic carbon content was determined according to ISO 14235:1998. Stones and fragments of plants were removed from the soil samples. Next, the soil was homogenised and dried on blotting paper until airdried. Finally, it was ground and sieved through a $0.8-\mathrm{mm}$ sieve. Since the objective of this study was the interaction between atrazine and mineral horizon of soil, the following procedure was applied to remove low-molecular hydrophobic compounds as well as any possible residues of the pesticide. One hundred grams of sieved soil was weighed into a $250-\mathrm{mL}$ conical flask, and $125 \mathrm{~mL}$ methylene chloride was added; UAE was conducted for $20 \mathrm{~min}$. This procedure was repeated three times. Subsequently, the solvent was decanted and the soil was air-dried. One millilitre of atrazine standard solution in methanol $\left(0.15 \mathrm{mg} \mathrm{mL}^{-1}\right)$ was added to $1 \mathrm{~g}$ of the prepared soil, and the sample was left in the dark at room temperature for $24 \mathrm{~h}$. After adsorption of atrazine, the extraction step was performed to establish the atrazine recovery depending on the type of soil (organic or mineral horizon).

\subsubsection{Sorbent preparation}

To $1 \mathrm{~g}$ of dried (at $180{ }^{\circ} \mathrm{C}$ for $24 \mathrm{~h}$ ) $\mathrm{SiO}_{2}$, the following substances were added:
A. $0.5 \mathrm{~mL}$ of water
B. $0.5 \mathrm{~mL}$ of $0.1 \mathrm{M} \mathrm{NaOH}$
C. $0.5 \mathrm{~mL}$ of $6 \mathrm{M} \mathrm{HCl}$

Subsequently, the samples were homogenised and left in the dark at room temperature for $24 \mathrm{~h}$. Next, $1 \mathrm{~mL}$ of atrazine solution in methanol $\left(0.15 \mathrm{mg} \mathrm{mL}^{-1}\right)$ was added, and the sample was left in the dark at room temperature for $24 \mathrm{~h}$. Each type of sample was prepared six times.

$\mathrm{Al}_{2} \mathrm{O}_{3}$ was calcinated at $405{ }^{\circ} \mathrm{C}$ for $24 \mathrm{~h}$. Next, $1 \mathrm{~mL}$ of atrazine solution in methanol $\left(0.15 \mathrm{mg} \mathrm{mL}^{-1}\right)$ was added to $1 \mathrm{~g}$ of sorbent, and the sample was left in the dark at room temperature for $24 \mathrm{~h}$.

\subsection{Extraction}

The ultrasound-assisted extraction was conducted for both the soil and sorbent samples (5.0 g). Methylene chloride was applied as a solvent $(55 \mathrm{~mL})$. The total extraction time was $60 \mathrm{~min}$ (in three 20-min stages each with fresh solvent). The extraction was conducted at room temperature. Next, the samples were filtrated, and the extracts were concentrated on a rotary evaporator to a volume of $1 \mathrm{~mL}$. Finally, the extract was completely dried to a dryness solid at room temperature. Before the chromatographic analysis, it was dissolved in $1 \mathrm{~mL}$ of hexane (Barchanska et al. 2013).

\section{Results and discussion}

The literature overview indicates that the atrazine recovery from soil samples is strongly influenced by the extraction technique, the $\mathrm{pH}$ of the soil and the herbicide's interaction with the organic and inorganic compounds in the soil matrix (Gonzalez-Pradas et al. 2003; Urena-Amate et al. 2005; Barchanska et al. 2013). The sorption and desorption processes of atrazine on soil components play an important role in its environmental behaviour. Efforts have been made to study the various physical and chemical mechanisms of atrazine sorption onto humic substances (Sposito et al. 1996) and clay minerals (Herwig et al. 2001), respectively.

Taking into account the diverse physico-chemical properties of heterogeneous soil, especially the coexistence of two different main components, i.e., organic matter (humic and fulvic acids) and mineral phase (mainly aluminosilicates), 
Fig. 1 FTIR spectra of $\mathrm{SiO}_{2}$ (a), $\mathrm{SiO}_{2}$ spiked with atrazine after extraction procedure (b), the spectrum obtained after subtracting spectrum a from spectrum $b(\mathbf{c})$ and spectrum of atrazine (d)
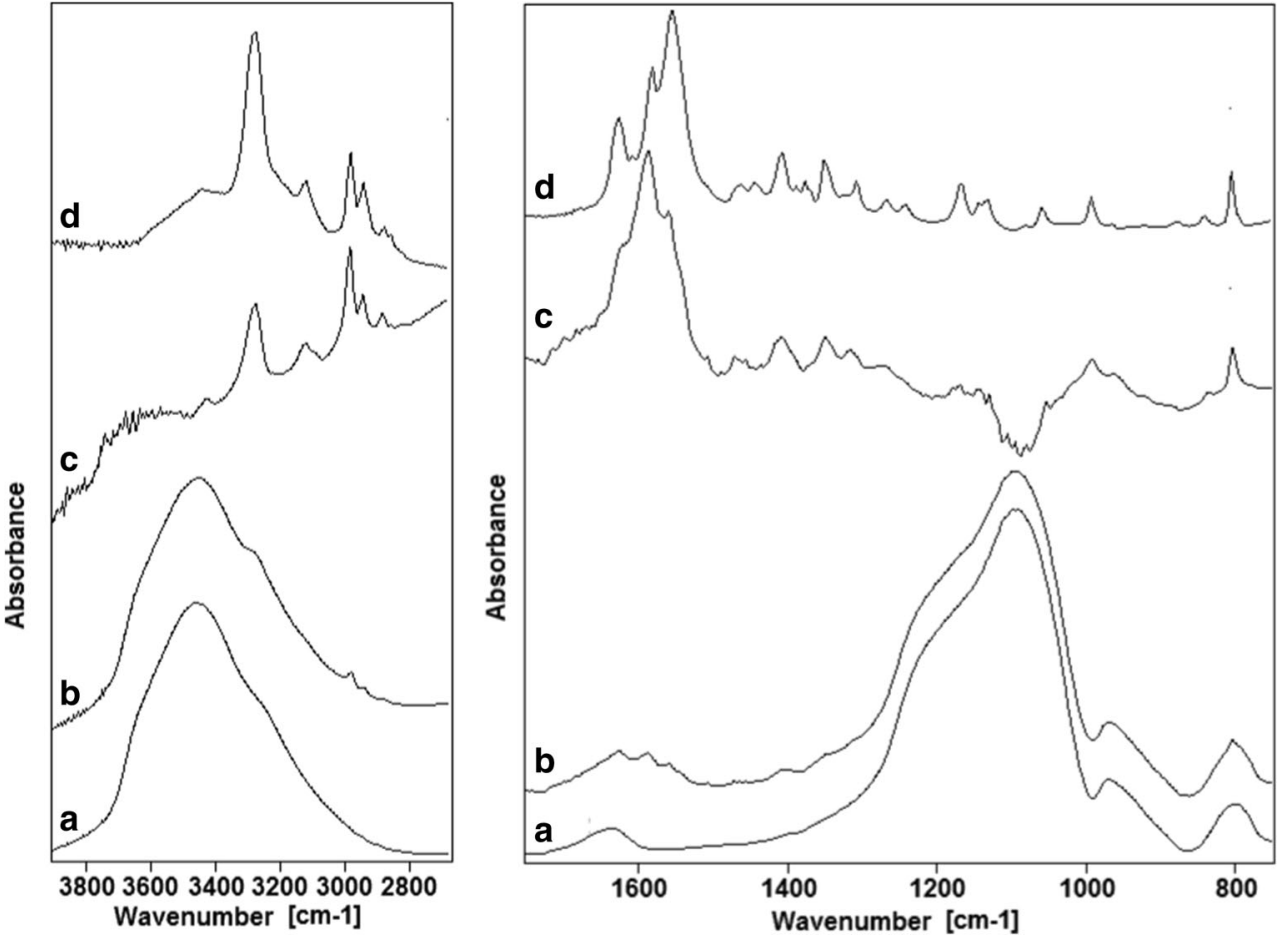

the effectiveness of atrazine extraction from soil is influenced by non-specific interactions between this herbicide and the soil matrix. To explain these interactions, three parallel series of soil samples were collected in forest areas from the upper layer (organic horizon), which contains humus, as well as from a depth of $1 \mathrm{~m}$, where the concentration of humus is considerably lower than in the organic horizon.

Low recovery of atrazine from soil samples obtained using ultrasound-assisted extraction was reported in earlier studies
(Baranowska et al. 2006; Barchanska et al. 2013). The effectiveness of extraction was not influenced by the type of solvent. Therefore, this assessment of the influence of soil $\mathrm{pH}$ and moisture content on atrazine sorption was undertaken. The organic horizon and mineral horizon exhibit different physical-chemical profiles, which are presented in Table 3. The organic carbon content, hydrolytic acidity and sorption capacity are higher for the organic horizon than for the mineral horizon, but the $\mathrm{pH}$ values of both horizons are similar. The
Fig. 2 FTIR spectra of $\mathrm{Al}_{2} \mathrm{O}_{3}($ a), $\mathrm{Al}_{2} \mathrm{O}_{3}$ spiked with atrazine after extraction procedure (b), the spectrum obtained after subtracting spectrum a from spectrum $b$ (c) and spectrum of atrazine (d)
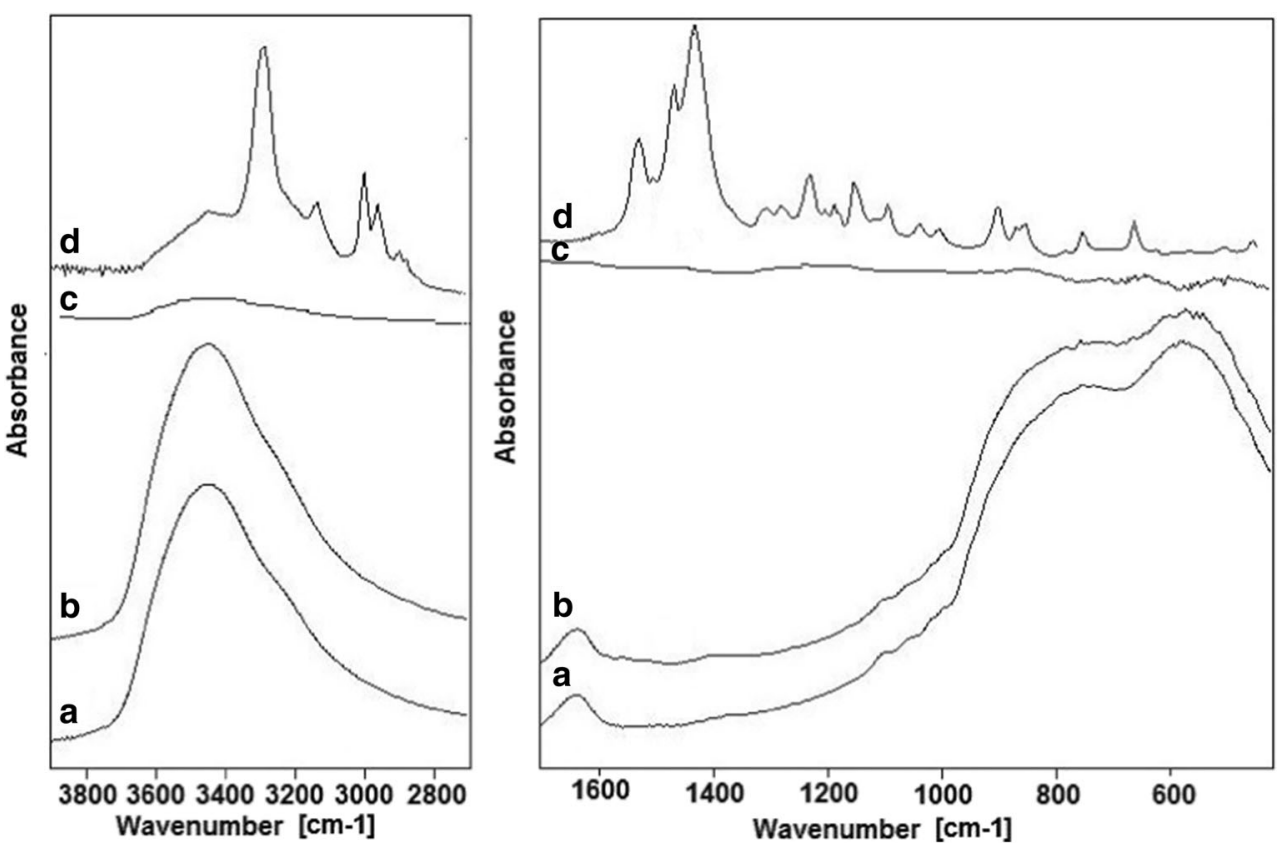
Table 3 Characteristic of investigated soil and atrazine recovery

\begin{tabular}{|c|c|c|}
\hline Parameter & Organic horizon & Mineral horizon \\
\hline $\mathrm{pH}$ in $\mathrm{H}_{2} \mathrm{O}$ & 6.20 & 6.30 \\
\hline Hydrolytic acidity, $\mathrm{Hh}\left(\mathrm{cmol}(+) \mathrm{kg}^{-1}\right)$ & 2.21 & 0.53 \\
\hline Sorption capacity (\%) & 8.50 & 3.49 \\
\hline Organic carbon content $(\%)$ & 18.45 & 0.60 \\
\hline Sum of exchangeable cations $(\%)$ & 6.29 & 1.23 \\
\hline \multicolumn{3}{|l|}{ Soil mineral composition $(\%)$} \\
\hline $\mathrm{MgO}$ & 0.25 & 0.37 \\
\hline $\mathrm{Al}_{2} \mathrm{O}_{3}$ & 1.45 & 6.37 \\
\hline $\mathrm{SiO}_{2}$ & 21.72 & 88.30 \\
\hline $\mathrm{K}_{2} \mathrm{O}$ & 0.66 & 1.56 \\
\hline $\mathrm{CaO}$ & 0.79 & 0.47 \\
\hline $\mathrm{Fe}_{2} \mathrm{O}_{3}$ & 0.59 & 1.30 \\
\hline $\mathrm{C}_{\text {total }}$ & 25.5 & 0.9 \\
\hline \multicolumn{3}{|c|}{ Atrazine recovery, \% (standard deviation, SD, \%) } \\
\hline & $63(4)$ & $15(3)$ \\
\hline
\end{tabular}

$n=3$
$\mathrm{XRF}$ analysis revealed that the mineral horizon contained $88 \% \mathrm{SiO}_{2}$ and $6.4 \% \mathrm{Al}_{2} \mathrm{O}_{3}$, while the organic horizon contained $21.7 \% \mathrm{SiO}_{2}$ and $1.45 \% \mathrm{Al}_{2} \mathrm{O}_{3}$ (Table 3). The recovery rates of atrazine from the organic horizon, which is rich in organic compounds, and the mineral horizon (1 m depth) are given in Table 3.

The obtained results show that the atrazine recovery rate (Table 3) was $63.1 \%$ for the organic horizon, whereas its recovery from the mineral horizon, where $\mathrm{SiO}_{2}$ dominates, was $15.4 \%$ (Table 3). In our previous research (Barchanska et al. 2013), the low recovery rate (15\%) of atrazine from soil samples was obtained using UAE rather than MAE, which had a recovery rate of approximately $84 \%$. Low atrazine recovery rates yielded by UAE were also noted by Lesueur et al. (2008) and Baranowska et al. (2006). The adsorption isotherms of this process indicate that desorption efficiency is low (Deng et al. 2010).

The differences in atrazine recovery from the organic and mineral horizons are most likely caused by the different compositions (ratio of organic matter to mineral compounds) of these soil layers. The obtained results indicate that the atrazine extraction efficiency was definitely lower for the mineral horizon, which exhibits a lower sorption capacity and sum of exchangeable cations than the organic horizon. This finding suggests an interaction between atrazine and the mineral components of soil, particularly $\mathrm{SiO}_{2}$ (Davies and Jabeen 2003). Deng et al. (2010) reported that the average percentage of atrazine that was desorbed from sandy loam soil was $32.3 \pm 6.0 \%$. These data suggested that atrazine would remain bound to the sandy loam soil. The interactions between organic and mineral compounds in soil are the result of van der Waals forces, cation bridges and ion exchange. The reason for ion exchange and chemical sorption is the negatively charged, non-compensated electric charges that occur on the surface of soil colloids. The adsorption of humic and fulvic acids onto the loamy minerals occurs in the presence of multivalent cations.

The influence of minerals on atrazine's behaviour in soil is not well known. Gonzalez-Pradas et al. (2003) and UrenaAmate et al. (2005) investigated the adsorption of atrazine onto kerolite $\left[\mathrm{Mg}_{3} \mathrm{Si}_{4} \mathrm{O}_{10}(\mathrm{OH})_{2} \cdot \mathrm{nH}_{2} \mathrm{O}\right]$. The results demonstrated that atrazine is adsorbed onto the kerolite surface as a non-ionic species. The adsorption mechanism possibly occurs via cation bridging, which involves the formation of an innersphere complex between the kerolite $\mathrm{Mg}^{2+}$ cations and the atrazine - $\mathrm{NH}$ group. Cation bridges are formed by multivalent cations, which are able to create the bonds with charges occurring on the surface of the minerals and functional groups of humic compounds (i.e., $\mathrm{COO}^{-}$). Usually, such bridges are formed by the following cations: $\mathrm{Ca}^{2+}, \mathrm{Fe}^{3+}$ and $\mathrm{Al}^{3+}$. Considering the composition of the mineral horizon (1.3\% $\mathrm{Fe}_{2} \mathrm{O}_{3}$ and $6.4 \% \mathrm{Al}_{2} \mathrm{O}_{3}$ ), this type of interaction should not significantly influence the atrazine adsorption.

According to Davies and Jabeen (2003), atrazine is adsorbed onto bentonite, montmorillonite and humic acid by protonation and through hydrogen bonding. The hydrolysis of atrazine occurred on the surface of kaolinite. The clay minerals in soil play a major role in the metabolisation of atrazine. Atrazine's hydrolysis to hydroxyatrazine and the formation of bound residues were mainly responsible for the observed hysteresis in its sorption and desorption isotherms.

$\mathrm{SiO}_{2}$ is the main mineral component of soil; therefore, for the investigation of the non-specific interactions between atrazine and mineral compounds of soil, this sorbent was chosen 
as a model. To estimate the influence of cation bridges formed by $\mathrm{Al}_{2} \mathrm{O}_{3}$, the sorption experiments were also conducted using alumina.

In the case of $\mathrm{Al}_{2} \mathrm{O}_{3}$, the mean recovery of atrazine was $86.5 \%$, while for $\mathrm{SiO}_{2}$, it was only $10.8 \%$. The detailed data are presented in Table 4.

The results of the elemental analysis of the $\mathrm{SiO}_{2}$-atrazine mixture, after herbicide extraction, revealed the presence of nitrogen in the $\mathrm{SiO}_{2}$ sorbent, which may suggest the presence of triazine residue in the silica gel.

These differences in atrazine extraction efficacy between $\mathrm{Al}_{2} \mathrm{O}_{3}$ and $\mathrm{SiO}_{2}$ resulted from the physical-chemical properties of atrazine (Table 1) and the properties of these sorbents (Table 2). To complete the description of the phenomena that occur in the mineral horizon of soil, the influences of water (pore solution) and $\mathrm{pH}$ were investigated in detail.

Atrazine was extracted from $\mathrm{SiO}_{2}$ as described in Sects. 2.3.2 (A-C) and 2.4. The effectiveness of atrazine desorption from $\mathrm{SiO}_{2}$ containing water $\left(0.5 \mathrm{~g} \mathrm{~g}^{-1}\right)$ was $4.9 \%$ and was lower in comparison with dry sorbent (Table 4). When the $\mathrm{pH}$ of the sorbent was 1.0, atrazine recovery was lower than $0.1 \%$. Similar results were obtained by Saint-Fort and Visser (1988) for the atrazine adsorption of clay minerals. The atrazine recovery rate was higher in alkaline conditions than in an acidic environment. The investigation of the $\mathrm{pH}$ dependence of the adsorption of atrazine onto silica gel was presented by Kovaios et al. (2010). They showed that the surface charge of the adsorbent is an important factor. A decrease of the solution $\mathrm{pH}$ from the equilibrium $\mathrm{pH}$ of 6.1 to 3.3 resulted in very little increase of the adsorbed atrazine. For higher $\mathrm{pH}$ values, the difference in atrazine adsorbed at the equilibrium $\mathrm{pH}$ was significant. The detailed results are presented in Table 4 .

Aluminium occurs in soils in both the soil solution and the solid phase. Porous alumina provides a weak Lewis acidity and basicity as well as a low Bronsted acidity; the $\mathrm{p} K_{\mathrm{a}}$ of the Bronsted sites is 8.5 (Grun et al. 1996). Weathering of primary minerals initially proceeds through hydrolytic breaking of the $\mathrm{Si}-\mathrm{O}-\mathrm{Al}$ linkages in the primary minerals, thereby releasing $\mathrm{Al}^{3+}$ to the aqueous phase (Hiradate et al. 1998). The presence of alumina ions enhanced atrazine hydrolysis because they act as Lewis acids (Comber 1999; Ghauch et al. 1999).

Different types of hydroxyl groups exist on the silica gel surface: free, isolated -OH groups; active, bonded with the same or contiguous silica atom; bonded, with two, three or four other-OH groups within 2.52-2.6 $\AA$; and geminate, $-\mathrm{OH}$ groups bonded with the same silica atom. The presence of $\mathrm{SiO}_{2}$ in soil caused an increase in the hydrophilic character of the surface; therefore, the water sorption is higher. Amorphous silica has a weak Bronsted acidity due to the silanol groups. At higher temperatures under laboratory conditions, silica can develop Lewis acidity and basicity due to the activation of siloxane groups during the course of dehydration (Grun et al. 1996, Kromidas 2005).
Table 4 Atrazine recovery study

\begin{tabular}{ll}
\hline Sorbent & $\begin{array}{l}\text { Atrazine recovery, \% } \\
\text { (standard deviation, SD, \%) }\end{array}$ \\
\hline $\mathrm{Al}_{2} \mathrm{O}_{3}$ & $86.3(0.3)$ \\
$\mathrm{SiO}_{2}$ (dry) & $10.8(0.2)$ \\
$\mathrm{SiO}_{2}(\mathrm{pH} 6.7)$ & $4.9(0.3)$ \\
$\mathrm{SiO}_{2}(\mathrm{pH} 1.0)$ & $<0.1$ \\
$\mathrm{SiO}_{2}(\mathrm{pH} 7.6)$ & $6.2(0.4)$ \\
\hline
\end{tabular}

$n=3$

Because the $\mathrm{pH}$ of $\mathrm{Al}_{2} \mathrm{O}_{3}$ is 9.5 , atrazine was in its molecular, non-hydrolysed form, in contrast to $\mathrm{SiO}_{2}$, which possesses acidic properties. Moreover, atrazine recovery from silicon dioxide may be influenced by the structure of this sorbent and a non-specific interaction between this herbicide and $\mathrm{SiO}_{2}$. As a result of interactions with the Bronsted acidic sites present on the silica gel surface, the retention of alkaline atrazine is higher than those obtained for alumina. The atrazine recovery rates from the studied sorbents are inversely proportional to their surface area.

Atrazine recovery from soil may also be influenced by the pore solution. Pore solutions contain dissolved sugars, fulvic acids and other organic acids, as well as inorganic compounds, such as nitrate, ammonium, potassium, phosphate, sulphate, calcium, zinc, iron and copper ions. These compounds are exchanged with the mineral and humic components of soil by adsorption. The soil $\mathrm{pH}$ can affect the type and number of ions that the soil solution contains. These ions can be exchanged between the soil and biological organisms. The organically bound $\mathrm{Al}$ in soil has been considered to be the major source of $\mathrm{Al}$ in solution, and its role in regulating $\mathrm{Al}^{3+}$ activity has been established (Matzner et al. 1998).

The recovery study suggests that the strength of the interaction forces between atrazine and the soil matrix compounds depends on the molecular form of the herbicide. In low $\mathrm{pH}$ conditions, atrazine exists in its protonated form, which is strongly bonded to the soil. In high $\mathrm{pH}$ conditions, atrazine is unprotonated; thus, it is weakly bonded to the soil matrix, which is in agreement with the findings presented by Browne (Browne et al. 1980). The influence of water content and the sorbent $\mathrm{pH}$ on the sorption of atrazine indicates the ionic character of the interaction between $\mathrm{SiO}_{2}$ and the herbicide.

To explain the mechanism of the interaction between atrazine and $\mathrm{SiO}_{2}$, Fourier transform infrared spectroscopy was applied.

\subsection{FTIR studies}

In a series of IR studies, Davies and Jabeen (2003) found that atrazine is adsorbed onto bentonite and montmorillonite by protonation and/or the formation of hydrogen bonds. The 
relatively small electrostatic effect measured may be attributed to the relatively low extent of atrazine protonation. Xing et al. (1996) also suggested that the azo and amino nitrogen atoms of atrazine can act as hydrogen bond acceptors with silanol groups or strongly adsorbed water molecules. In our studies of the nature of atrazine-silica gel interactions the FTIR method was used. The FTIR spectra obtained for $\mathrm{SiO}_{2}$, atrazine and the residue obtained after atrazine extraction from $\mathrm{SiO}_{2}$ are presented in Fig. 1.

The main features of the $\mathrm{SiO}_{2}$ spectrum are the characteristic band at $1093 \mathrm{~cm}^{-1}$ with a shoulder at $1200 \mathrm{~cm}^{-1}$ (Fig. 1), which corresponds to the $\mathrm{Si}-\mathrm{O}-\mathrm{Si}$ stretching vibrations. The broad peak with maximum at $3442 \mathrm{~cm}^{-1}$ corresponds to the stretching vibrations of hydroxyl groups and indicates the presence of water, which is additionally confirmed by a relatively weak peak at $1653 \mathrm{~cm}^{-1}$ (deformation vibrations of $\mathrm{OH}$ groups). In the atrazine spectrum, the bands observed at 3472 and $3272 \mathrm{~cm}^{-1}$ are characteristic of the amine groups, while these at 2974 and $2935 \mathrm{~cm}^{-1}$ are originated from $\mathrm{CH}_{3}$ and $\mathrm{CH}$ groups stretching vibrations. The bands attributed to the stretching vibrations of the 1,3,5-triazine ring appear at 1623, 1578 and $1552 \mathrm{~cm}^{-1}$. The band observed at $1552 \mathrm{~cm}^{-1}$ is partially overlapped by the band deriving from the deformation vibrations of the amine groups. In the region of 1450-1300 $\mathrm{cm}^{-1}$ appear several bands due to deformation vibrations of this ring and two bands characteristic of the deformation vibrations of the $\mathrm{CH}_{3}$ groups (1460 and $1348 \mathrm{~cm}^{-1}$ ). At $804 \mathrm{~cm}^{-1}$, middle intensity and relatively sharp band attributed to the stretching vibrations $\mathrm{C}-\mathrm{Cl}$ groups are observed. The remaining, rather, weak bands correspond to the deformation vibrations of the 1,3,5-triazine ring, $\mathrm{C}-\mathrm{H}$ groups (in triazine ring and in chains) and $\mathrm{C}-\mathrm{H}_{3}$ groups.

In the spectrum of the residue obtained after atrazine extraction from $\mathrm{SiO}_{2}$, bands originating both from $\mathrm{SiO}_{2}$ and atrazine can be found. After subtracting the $\mathrm{SiO}_{2}$ spectrum from the spectrum of the extraction residue, the final spectrum is similar to that of atrazine; however, some features are different. It concerns the region due to atrazine vibrations, especially the stretching vibrations; the bands at 1623,1578 and $1552 \mathrm{~cm}^{-1}$ shift to 1621,1587 and $1557 \mathrm{~cm}^{-1}$, respectively. Moreover, the proportions between them are changed. These changes indicate that 1,3,5-azidine ring interact with $\mathrm{SiO}_{2}$ molecule. In the spectrum obtained after subtraction of $\mathrm{SiO}_{2}$ spectrum from the residue obtained after atrazine extraction from $\mathrm{SiO}_{2}$, the bands attributed to the $\mathrm{N}-\mathrm{H}$ group stretching vibrations (3472 and $3272 \mathrm{~cm}^{-1}$ ) are quite the same as in the case of atrazine spectrum. It excludes the participation of the amine groups in interactions with $\mathrm{SiO}_{2}$. Additionally, in the FTIR spectrum of the residue obtained after atrazine extraction from $\mathrm{SiO}_{2}$, a difference in the shape of the $\mathrm{Si}-\mathrm{O}-\mathrm{Si}$ bands is observed. These changes confirm the presence of interactions between $\mathrm{Si}-\mathrm{O}$ groups from silica gel and 1,3,5-triazidine ring from atrazine and exclude the hydrogen bond formation in that case.
In opposite to $\mathrm{SiO}_{2}$, the spectrum of residue obtained after atrazine extraction from for $\mathrm{Al}_{2} \mathrm{O}_{3}$ is quite the same as that obtained for $\mathrm{Al}_{2} \mathrm{O}_{3}$ (Fig. 2). This confirms the lack of interactions between $\mathrm{Al}_{2} \mathrm{O}_{3}$ and atrazine.

\section{Conclusions}

1. The protonated atrazine exhibits stronger interactions with the soil mineral layer.

2. The results indicate that the soil $\mathrm{pH}$ influences atrazine behaviour in real soil samples. In acidic soil, atrazine remediation is limited, especially if the soil contains minerals with high $\mathrm{SiO}_{2}$ contents. This situation may cause the long-lasting persistence of atrazine in soil.

3. FTIR analysis of spiked sorbent after extraction procedure revealed that 1,3,5-azidine ring interacts with $\mathrm{SiO}_{2}$ molecule. The FTIR spectra do not unambiguously prove the existence of hydrogen bonds between atrazine and $\mathrm{SiO}_{2}$.

4. FTIR studies showed the lack of interactions between $\mathrm{Al}_{2} \mathrm{O}_{3}$ and atrazine.

Open Access This article is distributed under the terms of the Creative Commons Attribution 4.0 International License (http:// creativecommons.org/licenses/by/4.0/), which permits unrestricted use, distribution, and reproduction in any medium, provided you give appropriate credit to the original author(s) and the source, provide a link to the Creative Commons license, and indicate if changes were made.

\section{References}

Baranowska I, Barchanska H, Pacak E (2006) Procedures of trophic chain samples preparation for determination of triazines by HPLC and metals by ICP-AES methods. Environ Pollut 143:206-211

Barchanska H, Czaplicka M, Giemza A (2013) Simultaneous determination of selected insecticides and atrazine in soil by MAE-GC-ECD. Arch Environ Prot 39:27-40

Brodeur JC, Svartz G, Perez-Coll CS, Marino DJG (2009) Comparative susceptibility to atrazine of three developmental stages of Rhinella arenarum and influence on metamorphosis: non-monotonous acceleration of the time to climax and delayed tail resorption. Aqua Toxicol 91:161-170

Browne JE, Feldkamp JR, White JL, Hem SL (1980) Potential of organic cation-saturated montmorillonite as treatment for poisoning by weak bases. J Pharma Sci 69:1393-1395

Comber SDW (1999) Abiotic persistence of atrazine and simazine in water. Pest Sci 55:696-702

Davies JED, Jabeen N (2003) The adsorption of herbicides and pesticides on clay minerals and soils. Part 2. Atrazine. J Incl Phenom Macroc Chem 46:57-64

Deng J, Jiang X, Hu W, Hu L (2010) Quantifying hysteresis of atrazine desorption from a sandy loam soil. J Environ Sci 22:1923-1929

Farlin J, Gallé T, Bayerle M, Pittois D, Braun C, El Khabbaz H, Lallement C, Leopold U, Vanderborght J, Weihermueller L (2013) Using the long-term memory effect of pesticide and metabolite soil residues to estimate field degradation half-life and test leaching predictions. Geoderma 207:15-24 
Feria-Reyes RP, Medina-Armena P, Teutli-Leon M, Garcia-Jimenez MG, Gonzalez I (2011) A new approach for atrazine desorption, extraction and detection from a clay-silty soil samples. Am J Anal Chem 2:63-68

Filipov NM, Stewart MA, Carr RL, Sistrunk SC (2007) Dopaminergic toxicity of the herbicide atrazine in rat striatal slices. Toxicology 232:68-78

Garbin JR, Milori DMBP, Simoes ML, da Silva WTL, Neto LM (2007) Influence of humic substances on the photolysis of aqueous pesticide residue. Chemosphere 66:1692-1698

Geng Y, Ma J, Jia R, Xue L-q, C-j T, C-j L, Ma X, Lin Y (2013) Impact of long-term atrazine use on groundwater safety in Jilin Province. China J Integr Agric 12:305-313

Gevao B, Semple KT, Jones KC (2000) Bound pesticide residues in soils: a review. Environ Pollut 108:3-14

Ghauch A, Rima J, Amine C, Martin-Bouyer M (1999) Rapid treatment of water contaminated with atrazine and parathion with zero-valent iron. Chemosphere 39:1309-1315

Gilchrist GF, Gamble DS, Kodama H, Khan SU (1993) Atrazine interactions with clay minerals: kinetics and equilibrium of sorption. J Agric Food Chem 41:1748-1755

Gonzalez-Pradas E, Socias-Viciana M, Saifi M, Urena-Amate MD, Flores-Cespedes F, Fernandez-Perez M, Villafranca-Sanchez M (2003) Adsorption of atrazine from aqueous solution on heat treated kerolites. Chemosphere 51:85-93

Grun M, Kurganov AA, Schacht S, Schulz F, Unger KKK (1996) Comparison of an ordered mesoporous aluminosilicate, silica, alumina, titania and zirconia in normal-phase high-performance liquid chromatography. J Chromatogr A 740:1-9

Hase Y, Tatsuno M, Nishi T, Kataoka K, Kabe Y, Yamaguchi Y (2008) Atrazine binds to F1F0-ATP synthase and inhibits mitochondrial function in sperm. Biochem Biophys Res Comm 366:66-72

Herwig U, Klumpp E, Schwuger MJ, Narres HD (2001) Physicochemical interactions between atrazine and clay minerals. App Clay Sci 18: 211-222

Hiradate S, Taniguchi S, Sakurai K (1998) Aluminum speciation in aluminum-silica solutions and potassium chloride extracts of acidic soils. Soil Sci Soc Am J 62:630-636

Hutta R, Góra R, Halko R, Chalanyova M (2011) Some theoretical and practical aspects in the separation of humic substances by combined liquid chromatography methods. J Chromatogr A 1218:8946-8957

ISO 10390:2005 (2005) Soil quality - determination of $\mathrm{pH}$

ISO 14235:1998 (1998) Soil quality-determination of organic carbon by sulfochromic oxidation

Ji Y, Dong C, Kong D, Lu J (2015) New insights into atrazine degradation by cobalt catalyzed peroxymonosulfate oxidation: kinetics, reaction products and transformation mechanisms. J Hazard Mater 285:491-500

Kovaios ID, Paraskeva CA, Koutsoukos PG (2010) Adsorption of atrazine in packed beds. Global NEST J 12:279-287

Kromidas S (2005) More practical problem solving in HPLC. Weinheim, Wiley-VCH

Lesueur C, Gartner M, Mentlem A, Fuerhacker M (2008) Comparison of four extraction methods for the analysis of 24 pesticides in soil samples with gas chromatography-mass spectrometry and liquid chromatography-ion trap-mass spectrometry. Talanta 75:284-293

Li X, Wu T, Huang H, Zhang S (2012) Atrazine accumulation and toxic responses in maize Zea mays. J Environl Sci 24:203-208

Matzner E, Pijpers M, Holland W, Manderscheid B (1998) Aluminum in soil solution of forest soils, influence of water flow and soil aluminum pools. Soil Sci Soc Am J 62:445-454

Merini LJ, Bobillo C, Cuadrado V, Corach D, Giulietti AM (2009) Phytoremediation potential of the novel atrazine tolerant Lolium multiflorum and studies on the mechanisms involved. Environ Pollut 157:3059-3063
Mou RX, Chen MX, Cao ZY, Zhu ZE (2011) Simultaneous determination of triazine herbicides in rice by high-performance liquid chromatography coupled with high resolution and high mass accuracy hybrid linear ion trap-orbitrap mass spectrometry. Anal Chim Acta 76:149-156

Nachimuthu G, Halpin NV, Bell MJ (2016) Effect of sugarcane cropping systems on herbicide losses in surface runoff. Sci Total Environ 557558:773-784

Neto ML, Vieira EM, Sposito G (1994) Mechanism of atrazine sorption by humic acid: a spectroscopic study. Environ Technol 28:1867-1873

Norra S, Fjer N, Fanwei L, Chu X, Xie X, Stube D (2008) The influence of different land uses on mineralogical and chemical composition and horizonation of urban soil profiles on Qingdao. China J Soils Sed 8:4-16

Ouyang W, Huang W, Wei P, Hao F, Yu Y (2016a) Optimization of typical diffuse herbicide pollution control by soil amendment configurations under four levels of rainfall intensities. J Environ Manag $175: 1-8$

Ouyang W, Zhao X, Tysklind M, Hao F (2016b) Typical agricultural diffuse herbicide sorption with agricultural waste derived biochars amended soil of high organic matter content. Water Res 9:156-163

PPDB Pesticide Properties DataBase, accessed 12.06.2017

Prado B, Duwig C, Hidalgo C, Müller K, Mora L, Raymundo E, Etchevers JD (2014) Transport, sorption and degradation of atrazine in two clay soils from Mexico: andosol and vertisol. Geoderma 232234:628-639

Prosen H, Zupancic-Kralj L (2005) Evaluation of photolysis and hydrolysis of atrazine and its first degradation products in the presence of humic acids. Environ Pollut 133:517-529

Prosen H, Fingler S, Zupancic-Kralj L, Drevenkar V (2007) Partitioning of selected environmental pollutants into organic matter as determined by solid-phase microextraction. Chemosphere 66:580-1589

Roustan A, Aye M, De Meo M, Di Giorgio C (2014) Genotoxicity of mixtures of glyphosate and atrazine and their environmental transformation products before and after photoactivation. Chemosphere 108:93-100

Saint-Fort R, Visser SA (1988) Study of interactions between atrazine, diazinon and lindane with humic acids of various molecular weights. J Environ Sci Heal A 23:613-624

Sposito G, Martin-Neto L, Yang A (1996) Atrazine complexation by soil humic acids. J Environ Qual 25:1203-1209

Urena-Amate MD, Socias-Viciana M, Gonzalez-Pradas E, Saifi M (2005) Effects of ionic strength and temperature on adsorption of atrazine by a heat treated kerolite. Chemosphere 59:69-67

Wang D, Shin JY, Cheney MA, Sposito G, Spiro TG (1999) Manganese dioxide as a catalyst for oxygen-independent atrazine dealkylation. Environ Sci Technol 33:3160-3165

Weselak M, Arbuckle TE, Wigle DT, Krewski D (2007) In utero pesticide exposure and childhood morbidity. Environ Res 103:70-86

Wilhelms KW, Cutler SA, Proudman JA, Carsia RV, Anderson LL, Scanes CG (2006) Lack of effects of atrazine on estrogenresponsive organs and circulation hormone concentrations in sexually immature female Japanese quail (Coturnix coturnic japonica). Chemosphere 65:674-681

Xing B, Pignatello JJ, Gigliotti B (1996) Competitive sorption between atrazine and other organic compounds in soils and model sorbents. Environ Sci Technol 30:2432-2438

Yixin Y, Hongbin C, Pai P, Hongmiao B (2014) Degradation and transformation of atrazine under catalyzed ozonation process with $\mathrm{TiO} 2$ as catalyst. J Haz Mat 279:444-451

Yu Y, Cole RB (1997) Micellar electrokinetic capillary chromatography method for direct determination of herbicides in Lake Pontchartrain, Louisiana, sediments. Environ Sci Technol 31:3251-3257 